\title{
METASTASES OF CARCINOID TUMOURS
}

\author{
By Alfred Standeven, M.A., M.Chir., F.R.C.S. \\ Assistant to the Surgical Unit, St. Mary's Hospital
}

In 1930, Sir Maurice Cassidy described the case history of a young man with hepatic metastases from an abdominal tumour, who suffered from attacks of flushing of the skin of the face and who developed, while under observation, a systolic murmur over the precordium which at necropsy was found to be due to stenosis of the pulmonary valve. Several similar cases were recorded subsequently but it was not until Biörck et al. (1954) published their stimulating paper in which they described further cases and correlated the clinical features with the effects of serotonin (enteramine), now identified as 5.hydroxytryptamine, that interest in this distinctive syndrome was aroused. In the past two years cases have been recorded with increasing frequency as the condition has become better known, and over 20 cases are now on record. The syndrome comprises a carcinoid tumour of the alimentary tract with hepatic metastases, increased activity of the bowel, attacks of flushing of the skin, and pulmonary hypertension with, ultimately, changes in the pulmonary valve leading to stenosis.

\section{Clinical Features}

Carcinoid tumours arise from the Kultschitzky cells of the crypts of Lieberkuhn and may occur anywhere in the gastro-intestinal tract, including Meckel's diverticulum, and at any age, the earliest $I$ have seen being in the appendix of a girl of 9 years. The level of malignancy is low. One patient recorded by Thorson et al. had abdominal symptoms for 20 years before the tumour caused obstruction of the ileum, for the relief of which enteroanastomosis only was performed, and the patient survived for a further 16 years. In general the higher in the gastro-intestinal tract the tumour arises, the more likely is it to metastasise, and it is not until there are widespread hepatic metastases that the distinctive features of the syndrome make their appearance. The primary tumour may cause vague abdominal discomfort or the features of impending intestinal obstruction, but frequently is silent and the major complaint of patients suffering from this syndrome is of attacks of flushing of the skin of the face, upper limbs and upper part of the trunk, but sometimes of the whole body.

\section{Skin Changes}

The colour changes of the skin are subject to wide variation, but usually take the form of intermittent attacks of flushing during which a bright red erythema develops, beginning on the face and spreading steadily over the trunk and upper limbs to the hands, persisting for several minutes and then gradually fading. Occasionally the areas of fiery erythema alternate with patches of pallor and of macular cyanosis, the picture changing continually like a display of the Aurora Borealis, but such spectacular appearances are not often seen. During these attacks the patient may complain of burning and skin temperature recordings have shown that over the area of the flush the temperature may be as much as $9^{\circ} \mathrm{C}$. higher than in an adjacent unaffected area. The attacks of flushing occur spontaneously at varying intervals but frequently are induced by emotion, by meals and especially by the taking of alcohol. They may be accompanied by intestinal colic, borborygmi or even an attack of watery diarrhoea, by expiratory stridor or an asthmatic attack, and by general circulatory changes.

It is not uncommon for the patient to show a constant high colour, initially a bright or brick red and blanching on pressure but later becoming reddish-blue or even cyanotic and recalling the observation of Peacock that the cyanosis of pulmonary stenosis is a red-blue colour. Some patients show areas of erythema and of cyanosis which vary from time to time. Cyanosis, however, may occur in these patients before the development of pulmonary stenosis can be recognized and certainly in the absence of congestive heart failure. It is not influenced by breathing pure oxygen and it is not associated with polycythaemia. Nor can it be related in any way to bronchospasm and the full explanation of this phenomenon is as yet non-proven. Even against this background of colour the characteristic attacks can be recognized. Biörck et al. describe a young man of 19 years, who had a red-blue cyanosis which, when he 
became excited, changed to a sharp vermilion and appeared and disappeared in circular spots. Another patient with cyanosis of hands and face at rest developed periodically a deep reddish purple flush.

Other skin changes which have been noticed are telangiectases, which it is tempting to ascribe to failing liver function, and also areas of brown scaly thickening resembling pellagra which may be a sequel to the long-standing watery diarrhoea so common in this syndrome.

\section{Cardiovascular Effects}

The colour changes in the skin are the visual evidence of varying stages in contraction and dilatation of the arterioles and capillaries, changes which are sufficiently marked to affect the circulatory haemodynamics. During an attack of flushing the peripheral arteries pulsate vigorously due to increased pulse pressure, the pulse rate increases, and the patient may complain of giddiness and of blurred vision. Snow et al. describe one patient in whom the blood pressure rose during an attack, but in a second patient it fell so precipitately that even the carotid pulse could not be felt, leading on one occasion to loss of consciousness.

Sooner or later in these patients the pressure in the pulmonary circulation and in the right side of the heart becomes permanently raised, and over the precordium a harsh systolic murmur can be detected, which may be present only during the attacks of flushing. In one such case the heart valves appeared normal at post mortem examination. Characteristically, however, a true pulmonary valve stenosis develops, the right ventricle hypertrophies and dilates and ultimately oedema, ascites and the other features of congestive heart failure may appear. At post mortem examination the pulmonary valve shows a varying degree of fusion of the cusps with fibrosis and thickening, but with no evidence of active or past rheumatism, congenital heart disease or syphilis in the specimens examined. Tricuspid incompetence has also been observed.

\section{Alimentary Effects}

In most of the recorded cases increased bowel activity has been noted and in one patient a watery diarrhoea was an outstanding symptom both before and after removal of the primary tumour, suggesting that, in the absence of any other demonstrable cause, it was in some way related to the metastases.

Abdominal examination reveals in most cases enlargement of the liver presenting the features of secondary deposits, and the primary tumour or a mass of secondary deposits in the mesenteric group of para-aortic lymph glands may also be palpable.

\section{Aetiology}

Thorson et al. suggest that the features of this syndrome can be explained, in part at least, on the basis of the known actions of 5.hydroxytryptamine (5.HT). This substance was first detected in argentaffin cells in 1933 by Vialli and Erspamer, who named it enteramine, and was isolated from the blood as serotonin by Rapport et al. (1948). More recently it has been found in considerable amounts in the brain, particularly in the medial part of the thalamus and in the hypothalamus which are associated functionally with the sympathetic system, and there is some experimental evidence that in the cat it is concerned with the transmission of impulses through sympathetic ganglia.

Acting on the intestine 5.HT increases peristalsis by stimulating smooth muscle and it is thought to be a factor in the control of normal peristalsis. It is noteworthy that carcinoid tumours are always associated with hypertrophy of the adjacent muscle whereas all other malignant tumours of the intestine destroy the muscle. This observation suggests that carcinoid tumours are physiologically active and pharmacological assay was attempted by Fehrter (1936) and by Selberg (1941) but with inconclusive results. Lembeck (1953) however, succeeded in extracting at least $2.5 \mathrm{mg}$. of $5 . \mathrm{HT}$ per g. of tumour tissue and similar evidence of high tumour content has also been found by Page et al.

Starling and Verney (1925) noted that a powerful vasoconstrictor, which appeared spontaneously in blood allowed to clot, no longer appeared if blood were perfused through a lung, and it has long been the custom of pharmacologists wishing to perfuse an organ with blood to run it first through a lung to remove its vasoconstrictor properties. It has now been established that this vasoconstrictor is serotonin (5.HT) and that in the lung it is converted by amine oxidase to the physiologically inactive 5 hydroxyindole acetic acid (5 HIAA) which is excreted in the urine. In health the 5.HT secreted in the wall of the intestine and released into the portal blood is rapidly absorbed by the platelets and less than half is recovered from the serum after clotting. Any reaching the lung in the plasma is inactivated and probably no free $5 . \mathrm{HT}$ reaches the general circulation, suggesting that its only normal physiological action is on the intestine. The fraction absorbed on to the platelets may assist in the arrest of haemorrhage when released at a site of injury by producing vasoconstriction, and evidence has been brought forward that its 
vasoconstrictive powers have an adverse effect in coronary thrombosis and pulmonary embolism.

When injected intravenously pure serotonin produces vascular effects which are extremely variable in differing conditions and species, but the most constant is pulmonary hypertension, with which there is frequently an associated constriction of the bronchi. Intradermally it produces an intense venous spasm with local congestion and a deep red morbilliform rash without itch or wheal formation.

There is thus a remarkable similarity between the known actions of 5.HT and the features of this interesting syndrome, and it remains to assess the evidence that $5 . \mathrm{HT}$ is in fact the causative agent. In the first place, as mentioned above, it is established that carcinoid tumours and the metastases contain relatively large amounts of 5.HT. To ascertain how much of this reaches the circulation, Goble et al. collected blood simultaneously from the pulmonary and brachial arteries and found that the former contained twice as much $5 . \mathrm{HT}$ as the latter and much more than blood from the inferior vena cava below the hepatic vein. Waldenström and his colleagues collected blood from two patients during flushing attacks and found serum levels of $12 \mu \mathrm{g}$. and $15 \mu \mathrm{g}$. respectively compared with the normal 0.03 to $0.2 \mu \mathrm{g}$. per ml. of serum. As the primary tumour had been removed in each case they conclude that hepatic metastases actively secrete 5.HT. Snow et al. argue that when abnormal amounts of 5.HT are secreted the normal distribution between platelets and plasma may be upset and that serum estimations may not be very accurate guides, for the amount in the plasma may rise sharply once the platelets are saturated. They, therefore, assayed the amounts in platelets and in platelet poor plasma and in one case found the former to be $0.34 \mu \mathrm{g}$. (normal 0.06 ) and the latter $0.3 \mu \mathrm{g}$. per $\mathrm{ml}$. In a second case the figures were 0.08 and $0.16 \mu \mathrm{g}$. respectively. Even when allowance is made for the inaccuracies of biological assay it seems reasonable to conclude that the tumours do release comparatively large amounts of 5.HT into the general circulation.

If, then, the syndrome could be reproduced by intravenous injection of 5.HT the postulate would be proved, but unfortunately this is not so. The maximum dose which a patient will tolerate by instant intravenous injection is I mg., and such injections, though they cause an extremely unpleasant sensation of burning of the face, do not produce objective flushing, bronchoconstriction or detectable increase in peristalsis. This dose is far below the levels recorded during flushing attacks in patients and the hypothesis is not therefore necessarily invalidated. Tolerance to intra- venous $5 . \mathrm{HT}$ is rapidly acquired in animals by pushing the dose but so unpleasant are the effects that similar experiments have not been pursued in man.

A patient of Crile with a proved carcinoid tumour and metastases did not show the features of the syndrome despite a high urinary excretion of 5 HIAA suggesting that a large amount of $5 . \mathrm{HT}$ was in fact produced by the tumour masses, and a further difficulty is the failure of known serotonin antagonists to influence the flushing attacks in these patients. Experimentally lysergic acid diethylamide specifically inhibits the effects of $5 . \mathrm{HT}$ on the vessels of a perfused rabbit ear in concentrations as low as one in ro millions, but has no effect on patients. Ergotamine tartrate, 2 brom. D. lysergic acid diethylamide bitartrate and phentolamine have all been tried without effect. The similarity between the formulae of 5.HT and histamine and the resemblance between their cutaneous effects raised the suggestion that the skin flushing might be due to histamine, but all known antihistamine drugs have likewise proved powerless to prevent or relieve the attacks. We must, therefore, conclude that in the present state of our knowledge the cause of the syndrome is nonproven.

Of particular interest is the mode of production of the pulmonary valve stenosis. In view of the development of the lesion late in the course of the disease, and of the maximal concentration of 5.HT in the right side of the heart it is tempting to ascribe it to the effects of 5.HT itself or of the pulmonary hypertension induced. There is, however, no evidence that pulmonary hypertension from any other cause can produce organic changes in the pulmonary valve, and so far there is no experimental evidence that serotonin can damage the valve, so the cause of this phenomenon remains unknown.

\section{Diagnosis}

The clinical features of this syndrome are so distinctive that no difficulty should arise in making the diagnosis but it may be confirmed by the estimation of $5 . \mathrm{HT}$ in the blood or of 5 HIAA in the urine. As has been indicated the former is less reliable than the latter which can be done by a colorimetric method and yields figures of the order of 100 to $400 \mathrm{mg}$. compared with the normal daily output of 5 to $10 \mathrm{mg}$.

The electrocardiogram frequently shows right axis deviation even in the absence of clinical evidence of a heart lesion, and a barium meal usually shows rapid passage of the barium through the small intestine.

It should not be long before a relatively easy method is developed for the estimation of urinary 
5 HIAA and it will be interesting to see if this test will enable us to detect the presence of carcinoids before the syndrome becomes manifest and the patient incurable. If the condition is kept in mind in cases of unexplained abdominal pain or diarrhoea it should not be impossible, and certainly we should be able to detect recurrences.

\section{Treatment}

The prognosis for these patients is unpredictable for whereas one patient succumbed within nine months of his first attack of flushing, another survived for 36 years. At present it is not possible to prevent or control the flushing attacks by medical means and the treatment of choice is excision of the primary tumour and as many metastases as possible, and the relatively benign nature of the tumour encourages more radical surgery than would be justified with other intestinal tumours. A pre-operative knowledge of urinary 5 HIAA would thus be of great advantage in a doubtful case. Skilful anaesthesia is essential in these cases for, should an attack occur during operation, fall of blood pressure and bronchospasm may lead to great difficulties in management. The second of Snow's three cases flushed during operation, her blood pressure became unrecordable and she died 24 hours later. The following hitherto unrecorded case history, published by permission of Professor Rob, also illustrates this point.

For those patients with hepatic matastases which cannot be resected, intravenous colloidal radioactive gold $\left(\mathrm{Au}^{198}\right)$ which is concentrated in the liver may afford some temporary relief but the results so far have not been impressive.

\section{Case History}

A male patient aged $5^{8}$ years was admitted to hospital complaining of cough, shortness of breath on exertion and attacks of flushing of his skin. The cough had occurred sporadically since an attack of ' acute bronchitis' I4 years previously, for which he was off work for three weeks, but had never been severe. Shortness of breath, on exertion only, began two years before admission and had steadily worsened. About this time he noticed occasional attacks of flushing, particularly after breakfast, and these had gradually but steadily increased in frequency up to 12 a day. At first confined to the head and neck, in the past few months they had extended over the shoulders, chest and arms. There was no history of diarrhoea. The flushes were accompanied by a burning sensation.

On examination the face and neck were constantly red and there was a brown mottling of the legs which he said had been present no longer than two years. Venous pulsation was seen in the neck up to 3 in. above the sternal angle and there was oedema of the ankles. The heart was not clinically enlarged but there was a systolic murmur loudest at the apex and medial to this. Blood pressure varied from $160 / 110$ to $210 / 130$. Chest expansion was $\frac{3}{4}$ in. only and rhonchi were heard in all areas. The left lobe of the liver was enlarged almost to the umbilicus but no other masses were palpable in the abdomen.

During observation he was seen to have not only up to the 12 flushes he described, but many more minor ones of which he remained unaware. They occurred during the night also, sometimes wakening him, and it was noticed that the arrival of visiting surgeons always induced a major flush. The flushes were bright red with sometimes a bluish tinge but patches of red, blue or white were never seen to occur simultaneously.

\section{Investigations}

$\mathrm{X}$-ray chest, including screening. The diameter of the heart reached the upper limit of normal, but there was no evidence of cor pulmonale.

Barium meal. No lesion of the stomach. A considerable portion of the barium had reached the transverse colon in 45 minutes, but apart from this very rapid passage of the meal no abnormality was seen.

Occult blood. Was negative on six occasions.

$\mathrm{Hb}$. varied between 90 and roo per cent. W.B.C. normal $(6,000$ to 7,000$)$.

Liver function tests. Serum protein $6.5 \mathrm{~g}$. per cent., albumen 4.I, globulin 2.4, with normal electrophoretic pattern.

Alkaline phosphatase, I3 units; Thymol turbidity, I unit; Serum bilirubin, $0.3 \mathrm{mg}$.

Blood urea, $39 \mathrm{mg}$. per cent.

Urine, normal.

5. Hydroxytryptamine Estimations:

Platelets before flush, $0.5 \mathrm{I} \mu \mathrm{g}$. per $10^{8}$ platelets Platelets after flush, $0.57 \mu \mathrm{g}$. per $10^{8}$ platelets. Platelet poor plasma before flush, $64 \mathrm{ng}$./cc. Platelet poor plasma after flush, $80 \mathrm{ng}$./cc.

Daily urinary output of 5 hydroxyindole acetic acid varied between 100 and $300 \mathrm{mg}$.

At laparotomy a large growth was present in the left lobe of the liver and a needle biopsy was performed. Several tumours were found in the ileum. During the operation he had several attacks of bronchospasm which were controlled with aminophylline $0.75 \mathrm{~g}$.

The diagnosis now being confirmed and the right lobe of the liver apparently free from metastases, it was decided to attempt removal of the left lobe of the liver and of the intestinal tumours. Premedication was chlorpromazine 25 mg., phenergan $25 \mathrm{mg}$. and pethidine roo $\mathrm{mg}$. 


\title{
M E D I C A L ETH I CS
}

edited by MAURICE DAVIDSON, D.M. (oxon.), F.R.C.P. (Lond.)

Consulting Physician, Brompton Hospital

$x+165$ pp., 1 illustration (1957). About 20s. net. Ready shortly

A new monograph

\section{PULMONARY COMPLICATIONSOF A B D O M I NAL SURGERY}

\author{
by A. R. ANSCOMBE, M.S. (Lond.), F.R.C.S. (Eng.) \\ Senior Lecturer in Surgery and Honorary Consultant, St. George's Hospital
}

Surgeons, anaesthetists and physicians, who have care of patients after operation, cannot fail to be stimulated by the problem of post-operative pulmonary complications as described in this book. These all too frequent complications are shown to be due to the effect of the abdominal operation on the mechanical function of the lungs; an effect which may be so severe as to cause the death of some patients in the immediate post-operative period. A simple method of estimating pulmonary function is described, and much evidence produced to show that such an estimation is essential in patients before an abdominal operation.

$$
x+121 \text { pp., } 37 \text { illustrations (1957) 20s. net. Ready shortly }
$$

\section{LLOYD-LUKE (Medical Books) Ltd., 49, Newman Street, W.I}

by intramuscular injection. Anaesthesia was high spinal, nitrous oxide and oxygen. As the primary tumour was freed the patient developed severe bronchospasm which resisted all attempts at manual inflation of the lung. Injections of brominated lysergic acid $6 \mathrm{mg}$. and of aminophylline (I g. repeated twice) were without effect and the heart stopped, but was started by cardiac massage. The patient was returned to the ward with assisted respiration but died three days later without regaining consciousness.

Necropsy showed four carcinoid tumours on the antimesenteric border of the ileum with no evidence of lymphatic metastasis. The liver contained a large deposit in the left lobe with a necrotic centre, and approximately 4 in. in diameter, and also several small deposits in the right lobe. The tricuspid valve was mildly stenosed. The pulmonary valve was thickened with a rolled edge and appeared incompetent.

5. Hydroxytryptamine content of tumours was estimated as $0.8 \mathrm{mg}$. per $\mathrm{g}$. in the primary and $0.7 \mathrm{mg}$. per $\mathrm{g}$. in the liver.

\section{BIBLIOGRAPHY}

AMIN, A. H., CRAWFORD, T. B. B., and CADDUM, J. H. BIORCK, G., AXXEN, O., and THORSON, A. (1952), Amer. Heart $\mathcal{Y . , ~}_{44} 143$.
BRANWOOD, A. W., and BRAIN, A. D. (1954), Lancet, ii, 1259. BRITISH MEDICAL JOURNAL (1954), ii, I44.

Ibid. (1956), i, 907.

Ibid. (1956), 1,1222

CASSIDY,' M. A. (1930), Proc. roy. Soc. Med., 24, 139.

CASSIDY, M. A. (1934), Ibid., 27, 220.

CURRENS, J. H., KINNEY, T. D., and WHITE, P. D. (1945),

A Amer. Heart \%. 30, 491. I. D., and GIBBONS, J. L. (1955), Brit. med. $\{$., ii, 1586 .

ERSPAMER, V.' (1955), F. Physiol (Lond.), 127, 118.

FEHRTER, F., and UNNA, K. (1936), Virchows Arch. path. Anat., $298,187$.

FRASER, I. (I955), Lancet, ii, 174.

GADDUM, J. H. (1953), Y. Physiol. (Lond.), 121, 151.

GADDUM, J. H., and HAMEED, A. GOBLLE, A. J., HAY, D. R., and SANDLER, M. (1955), Lancet,

HARDISTY, R. M., and STACEY, R. S. (1955), Y. Physiol(Lond.)., ISLER, P., and HEDINGER, C. (1953), Schweiz. med. Wschr., 83,4 .

JENKINS , J. S., and BUTCHER, P. J. A. (1955), Lancet, i, 33 r. JEPSON, J. B. (I955), Ibid., ii, 1009.

LEMBECK, F. (1953), Nature (Lond.), I72, 910. SJOERDSMA, A., and WEISSBACH, H. (1955), Lancet, i, 198 .

PEACOCK, T. B. (1866), ' On Malformation of the Human Heart,' 2nd Ed., Churchill, London.

PERNOW, B., and WÁLDENSTROM, J. (1954), Lancet, ii, 951. RAPPORT, M. M., GREEN, A. A., and PAGE, I. M. (1948),

F. biol. Chem. I74, 735.
REID, G., and RAND, M. (1952), Nature (Lond.), 169, 801.

REID, G., and RAND, M. (1952), Nature (Lond.), I69, 801. (1953), F. Lab. clin. Med., 42, 94I.

SELBERG, W. (1941), Klin. Wschr., 20, 127 r.

SMITH, G., and SMITH, A. N.' (1955), Surg. Gynec. Obstet., ror, 69r.

作, D., LENNARD JONES, J. E., CURZON, G., and THORSON, A., BIORCK, G., BJORKMAN, G., and WALDEN-

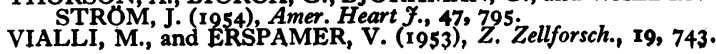

